\title{
Long-Term Exposure of Pressed Plutonium Oxide Heat Sources to Aquatic Environments
}

\author{
R. C. Heaton \\ J. H. Patterson \\ S. T. Kosiewicz \\ G. M. Matlack \\ F. J. Steinkruger \\ G. B. Nelson* \\ N. E. Vanderborgh \\ K. P. Coffelt \\ B. Herrera
}

\begin{abstract}
DISCLAIMER
This report was prepared as an account of work aponsored by an agency of the United States Goverament. Neither the United Statea Government nor any ajency thereof, nor any of their employea, makes any warranty, express or impliod, or assumes any lezal liability or responsibility for the accuracy, completenew, or usefulnets of any information, apparatus, product, or proces disclowed, or represents that its use would not infringe privately owned rights. Reference herein to any specific commercial product, procent, or service by trade name, trademark, manufecturer, or otherwise does not neceasarily contitute or imply its endornement, recommendation, or favoring y the United States Government or any agency theroof. The viewa and opiniona of authors exprescod herein do not necensurily state or reflect thowe of the United States Government or any asorcy thereof.
\end{abstract}




\title{
LONG-TERM EXPOSURE OF PRESSED PLUTONIUM OXIDE HEAT SOURCES TO AQUATIC ENVIRONMENTS
}

\author{
by
}

\author{
R. C. Heaton, J. H. Patterson, S. T. Kosiowicz, \\ G. M. Matlack, F. \&. Steinkruger, G. B. Nelson, \\ N. E. Vanderborgh, K. P. Coffelt, and B. Herrere
}

\begin{abstract}
Plutonium-238 oxide fuel pellets were exposed to water for 2.5 to $6.4 \mathrm{yr}$, ard the concentration of plutonium in the water was monitored. Water composition and temperature were found to be important factors in determining the rate of plutonium release into the water. Typical reloase rates ranged from 18 to 40 $\mathrm{ng} / \mathrm{m}^{2} / \mathrm{s}$ in cold fresh water and frem 0.3 to $11 \mathrm{ng} / \mathrm{m}^{2} / \mathrm{s}$ in cold sea wator. Relesese rates in sea water varied over time and sometimes were erratic. The piutonium release per unit area did not depend on the size of the $\mathrm{PuO}_{2}$ source.

The released plutonium was in an extremely fine form, able to pass through 10000 molecular weight cutoff filters. Apparent differenses in tha tuel pollot surfaces after exposure suggest that plutonium release is controlled by physical and chemical processes occurring at the solid-fiquid interface. Reloase mechanisms and their implications are discussed.
\end{abstract}

\section{INTRODUCTION}

Radioisotope thermoelectric generators, fueled with ${ }^{238} \mathrm{PuO}_{2}$, are used to power satellites and deep space probes when long-term, reliable power sources are needed and when other more conventional power supplies are unsuitable. Because these spacecraft function outside the earth's biosphere, the radioactive fuel sources offer no environmental risk under normal circumstances. However, if the spacecraft returned to earth through orbital decay, or if they failed to escape from earth because of a launch failure, significant amounts of plutonium could be released into the environment. The fuel containers have been designed to contain the radioactive fuel in all conceivable deposition situations, including reentry and launch pad explosions. Nevertheless, the Department of Energy continually seeks information on the behavior of the fuel sources and their containments in simulated environments to aid in risk assessment and safety analysis efforts and to assist in the design of improved fuel structures and containments.

The experiments described in this report were intended to simulate the deposition of unclad plutonium oxide fuel pellets into aqueous environments. This situation corresponds to the worst possible case in which the containment of a fuel pellet is completely destroyed and the fuel pellet is exposed directly to water. Our experimental objective was to determine the amount of plutonium released into the water under a variety of conditicns and to infer potential effects on the biosphere. In addition, such informaticn may be useful in future radioisotope heat source designs. The experiments themselves were discussed during their implementation. ${ }^{1-4}$ This report describes the experiments in their entirety and draws conclusions from the data. 


\section{EXPERIMENTAL SECTION}

Aquaria for these experiments, from Aquarium Systems, Inc., models CS25 and CS30, were equipped with both electrical heaters and refrigeration systems to maintain the desired operating temperature. Air bubblers were used to maintain water circulation within the chambers. Except for the glass fronts, the aquaria were constructed of plastic-coated plywood. The sides were extended 6 in. with 3/8-in.-thick Plexiglas, and the tops were covered with Plexiglas sheets. Vent holes in the tops were connected to the building's filtered exhaust system, and inlets were fitted with HEPA filters. Every joint and seam was sealed with silicone. These measures were undertaken to prevent the escape of airborne radioactive contamination from the aquaria into the surrounding work areas. The maximum volumes of the aquaria were approximately 90 or $110 \mathrm{~L}$ ( 29 gal.), depending on the aquarium model number.

Two types of water were used for these experimenis. Deionized water was used as a fresh water simulant in half of the experiments. Simulated sea water (Instant $\mathrm{Ocean}^{\mathrm{TM}}$, a product of Aquarium Systems, Inc.) was used in the other half. Table A-l in the Appendix shows the composition of the sea water.

The fuel sources were pressed plutonium oxide (PPO) fuel pellets manufactured at Los Aiamos National Laboratory, and the plutonium was 80 to $83 \%{ }^{238} \mathrm{Pu}$. Four of the pellets were pressed from a mixture of plutonium particle sizes (GROG), and pellet sizes ranged from approximately 6.1 to $64 \mathrm{~g}$. Specifications for the fuel pellets are shown in Table A-II.

At the beginning of each experiment, a fuel pellet was placed in an aquarium on a pedestal about 2 in. above the tank bottom. The water levels in the aquaria were kept approximately constant by adding deionized water. Water samples wera withdrawn periodically (weekly in most cases) and analyzed for plutonium concentration. At the conclusion of the experiments, the sources were removed and subjected to postmortem analyses by photographic and metallographic techniques. Several aquaria were monitored after their sources were removed to observe any changes in the plutonium content of the water without the complicating influence of the fuel pellets. Experimental details are shown in Table A-III. Water samples from four of the aquaria were characterized by filtration through fitters of varying sizes: $1.0-\mu \mathrm{m}$ Nuclepore ${ }^{\mathrm{TM}}, 0.1$ $\mu \mathrm{m}$ Nuclepore ${ }^{\mathrm{TM}}$, and 10000 molecular weight cutoff Amicon $^{T M}$ filters. This filtration was done to gain some insight into the particle size tribution of the water-borne plutonium. ${ }^{5}$

Plutonium analyses were conducted by liquid scintillation counting in a Packárd Tricarb ${ }^{T M}$ scintillation counter. Filters were completely dissolved, and the resulting solutions were counted as described above. Nuclepore filters were dissolved with Protosol ${ }^{\mathrm{TM}}$, a commerciaily available formulation used to dissolve tissue samples. Amicon filters were dissolved by sealed digestion with $90 \%$ nitric acid.

After they were removed from the aquaria, the sources were sectioned with a slow diamond saw and mounted in epoxy. The surfaces of the sections were ground smooth with 400 - to 600 grit silicon carbide paper and then were polished with $0.3-\mu \mathrm{m}$ alumina on a nylon cloth. They were etched by exposing them for $35 \mathrm{~min}$ to a mixture of $27 \mathrm{~mL}$ of $\mathrm{HBr}, 3 \mathrm{~mL}$ of $\mathrm{HCl}$, and 10 drops of HF. The surfaces were examined under green light by using a Zeiss Axiomat metallograph.

\section{RESULTS AND DISCUSSION}

The plutonium concentraticins found in the aquariuri waters as functions of time are shown in Figs. 1 to 10. These are gross concentrations and do not account for the possible chemical or physical forms present. Because the aquarium volumes are constant, the concentrations can be easily converted to the total plutonium contents of the aquarium waters.

In the fresh water experiments, the plutonium contents seem to increase apprioximately linearly with time. There may be small dips in the concentration curves for all except the cold water tank with the GROG source (fig. 2). This dip is much more pronounced in the warm water tank (Fig. 7) than in any others. Because we conducted only one warm íresh water experiment, it is difficult to say whether this observation is significant. Most large fresh water bodies are cold, so it probably is reascnable to model any fresh water deposition of a plutonium oxide source with a constant release rate.

The sea water aquaria all showed erratic behavior, except for the warm water tank containing the 6-g source (Fig. 10). In aquaria containing cold sea water, the plutonium concentrations increased for a time and then decreased. The initial increases can be approximated reasonably well with linear curves, but the decreases tend to behave more complexly. Aquaria 


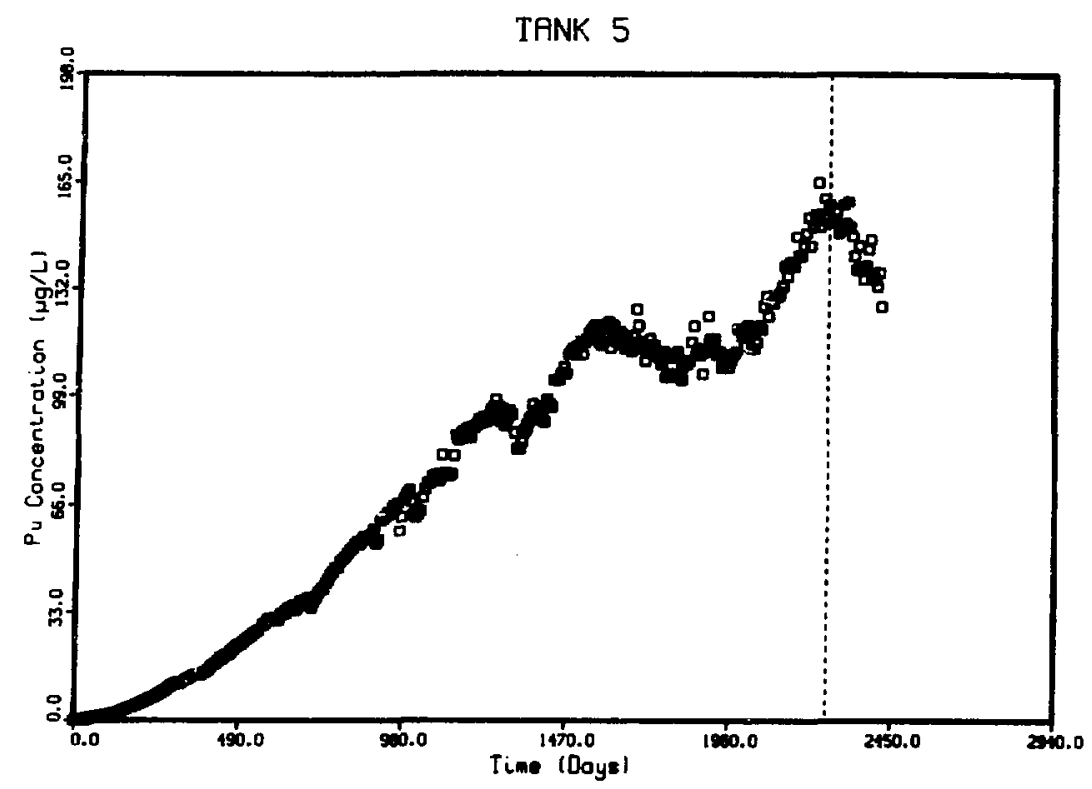

Fig. 1. Plutonium concentration versus time for aquarium number 5 (cold fresh water with a 63.2-g source). The vertical dashed line indicates removal of the source from the aquarium.

TANK 24

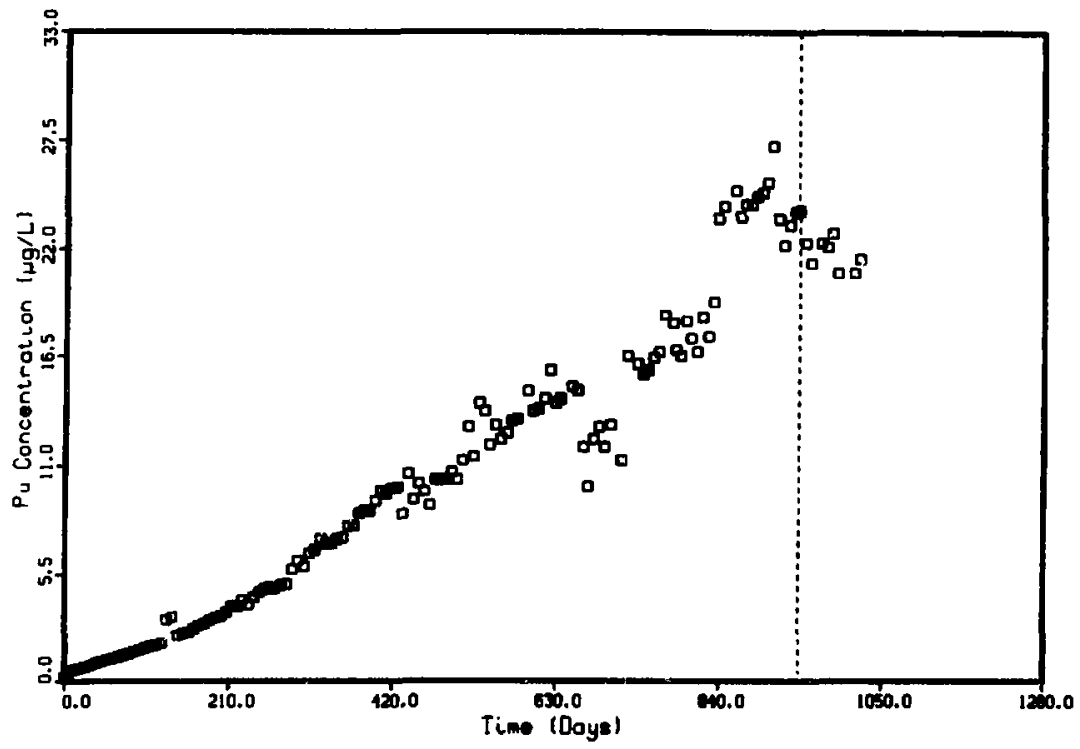

Fig. 2. Plutonium concentration versus time for aquarium number 24 (cold fresh water with a 33.6-g source). The vertical dashed line indicates removal of the source from the aquarium. 


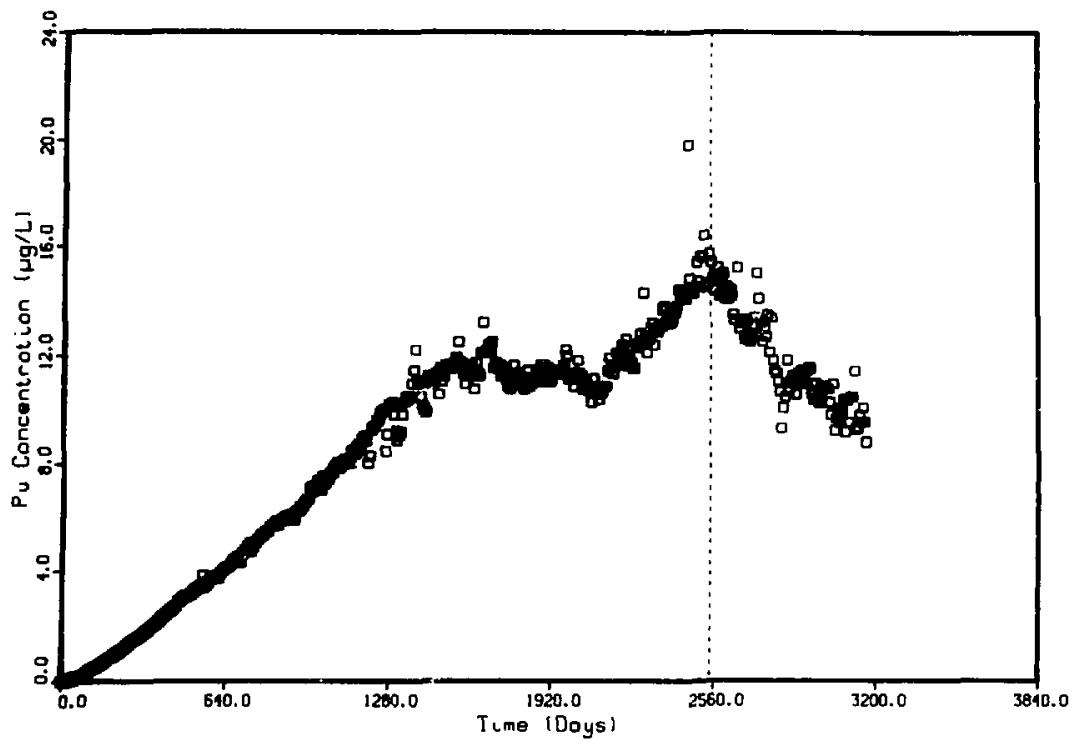

Fig. 3. Plutonium conceritration versus time for aquarium number 11 (cold fresh water with a 6.3-g source). The vertical dashed line indicates removal of the source from the aquarium.

TANK 13

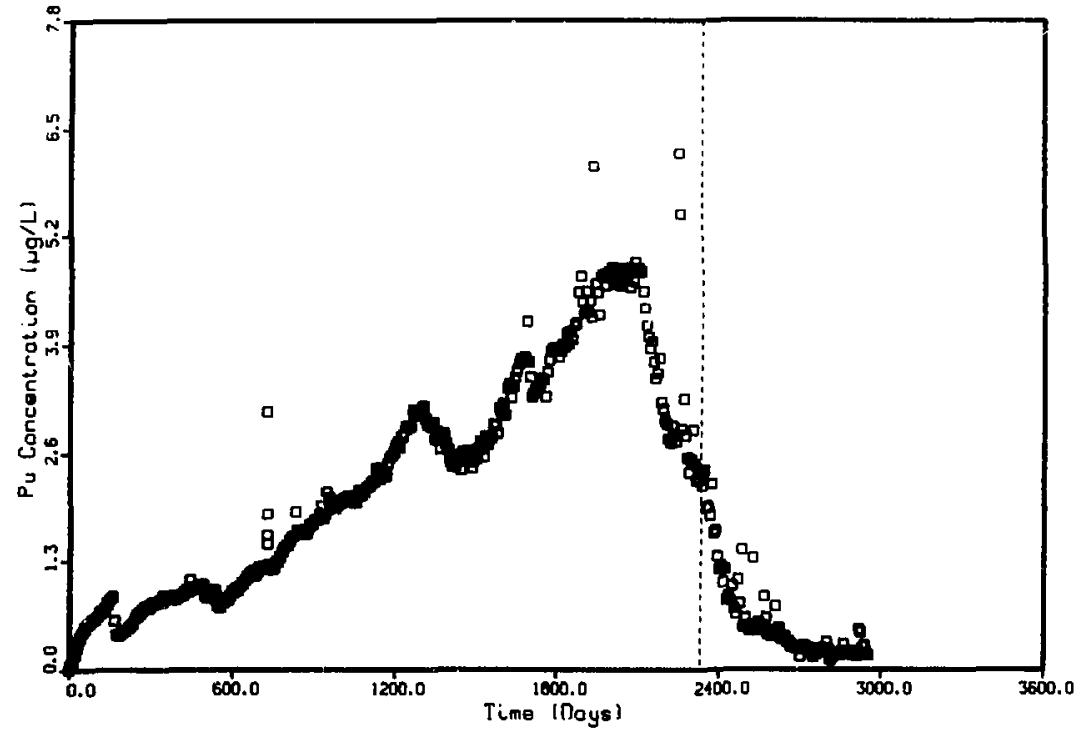

Fig. 4. Plutonium concentration versus time for aquarium number 13 (cold sea water with a 63.2-g source). The vertical dashed line indicates removal of the source from the aquarium. 
TANK 22

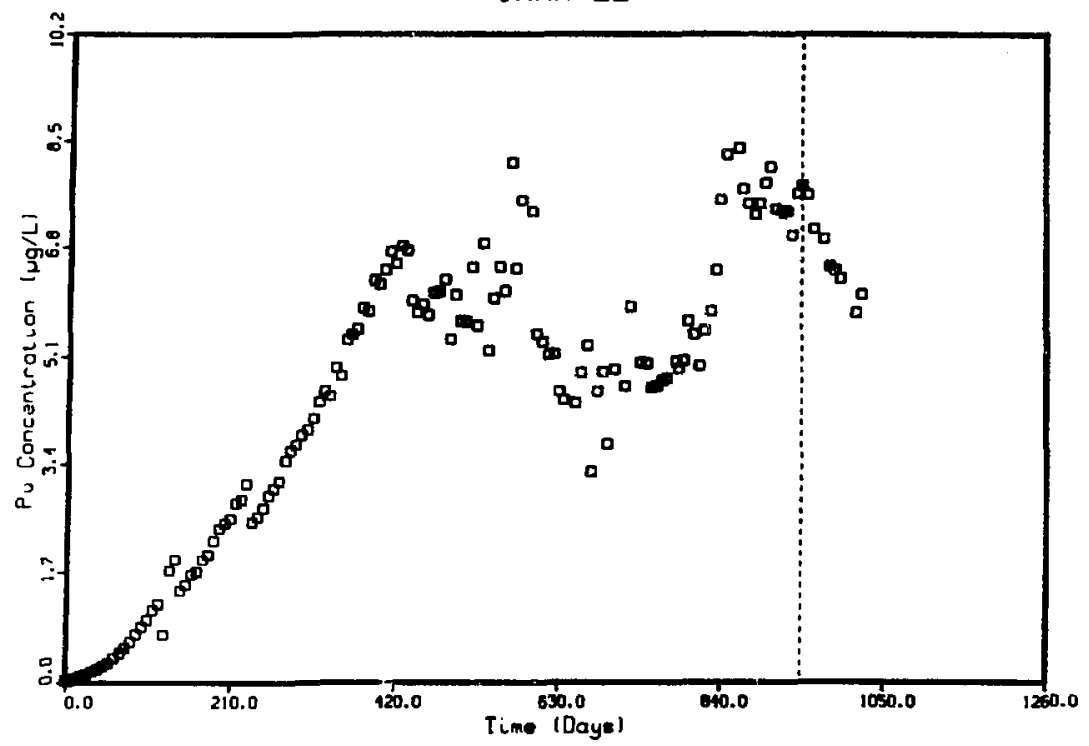

Fig. 5. Plutonium conctiiliation versus time for aquarium number 22 (cold sea water with a 33.6-g source). The vertical dashed line indicates removal of the source from the aquarium.

TANK 7

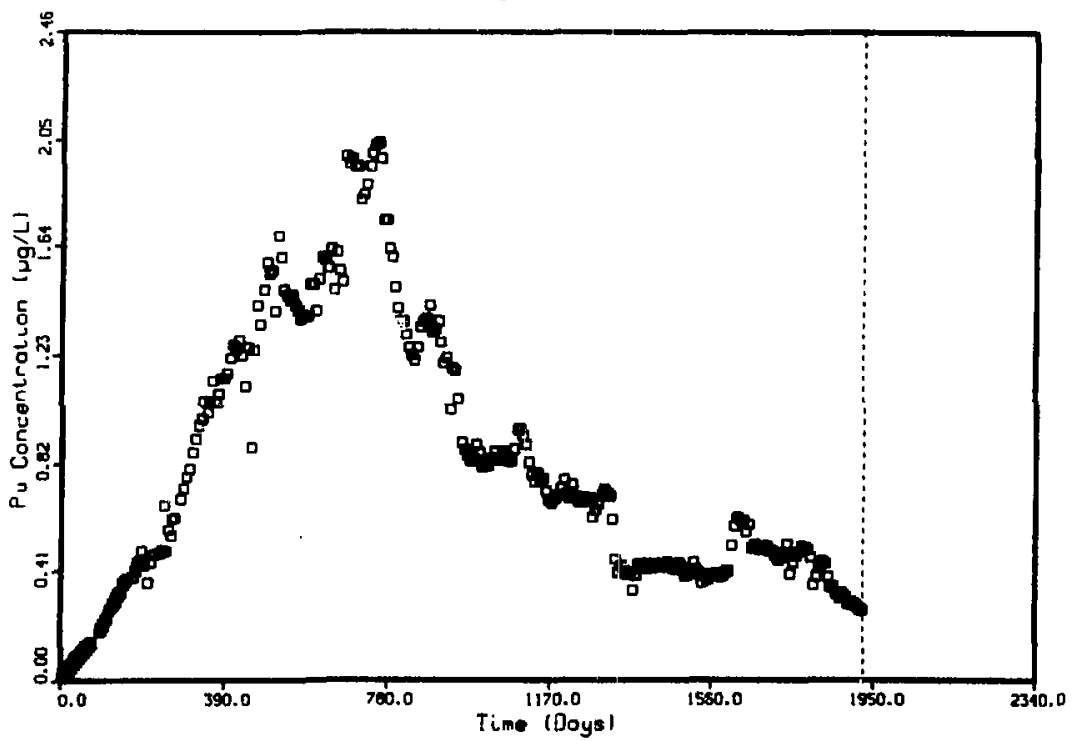

Fig. 6. Plutonium concentration versus tirne for aquarium number 7 (cold sea water with a 6.1-g source). The vertical dashed line indicates removal of the source from the aquarium. 
TANK 23

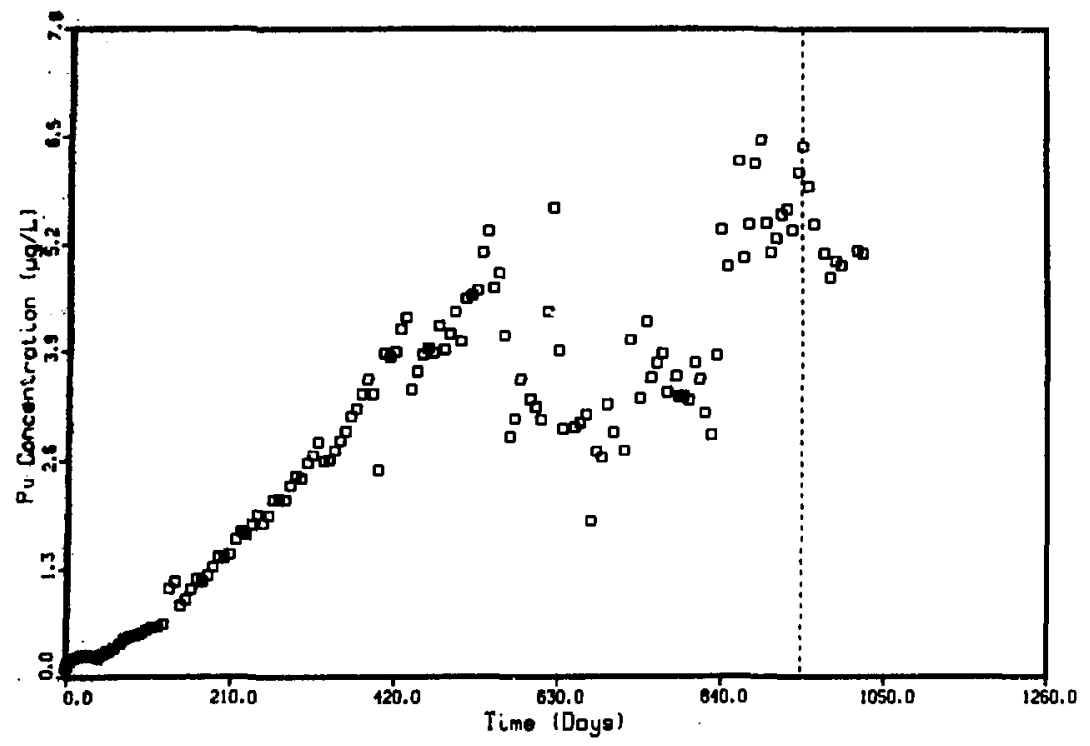

Fis. 7. Plutonium concentration versus time for aquarium number 23 (warm fresh water with a $33.5-\mathrm{g}$ source). The vertical dashed line indicates removal of the source from the aquarium.

TANK 12

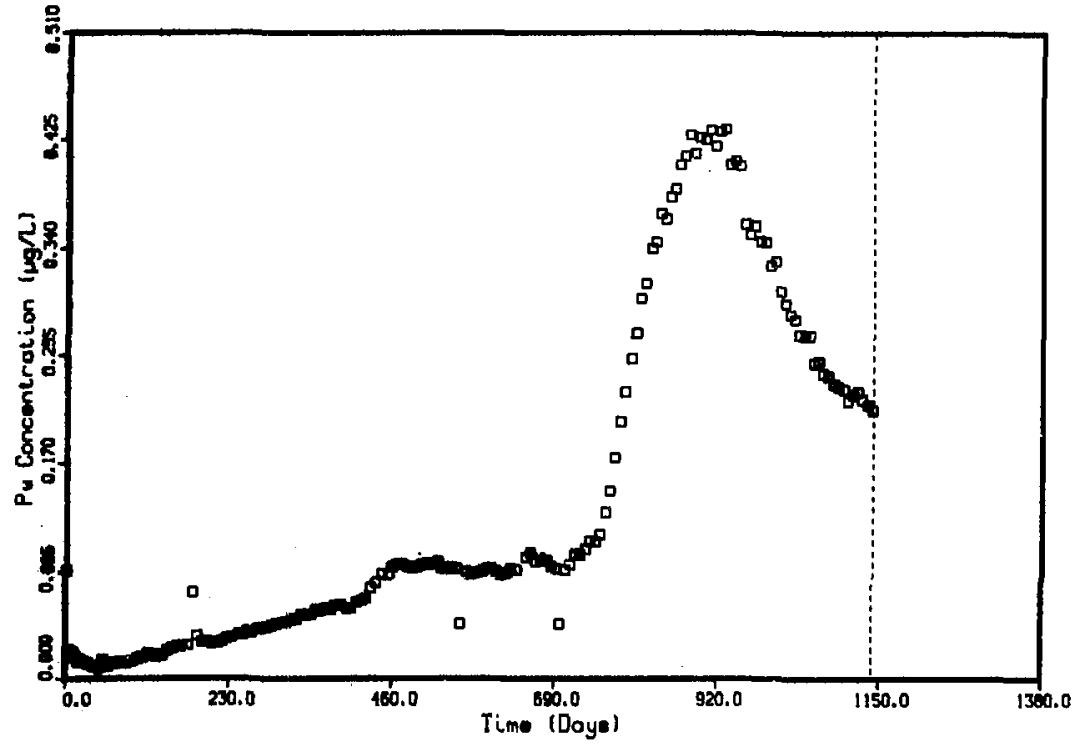

Fi. P. Putonium concentration versus time for aquarium number 12 (warm sea water with a 63.2-g source). The vertical dashed line indicates removal of the source from the aquarium. 
TANK 21

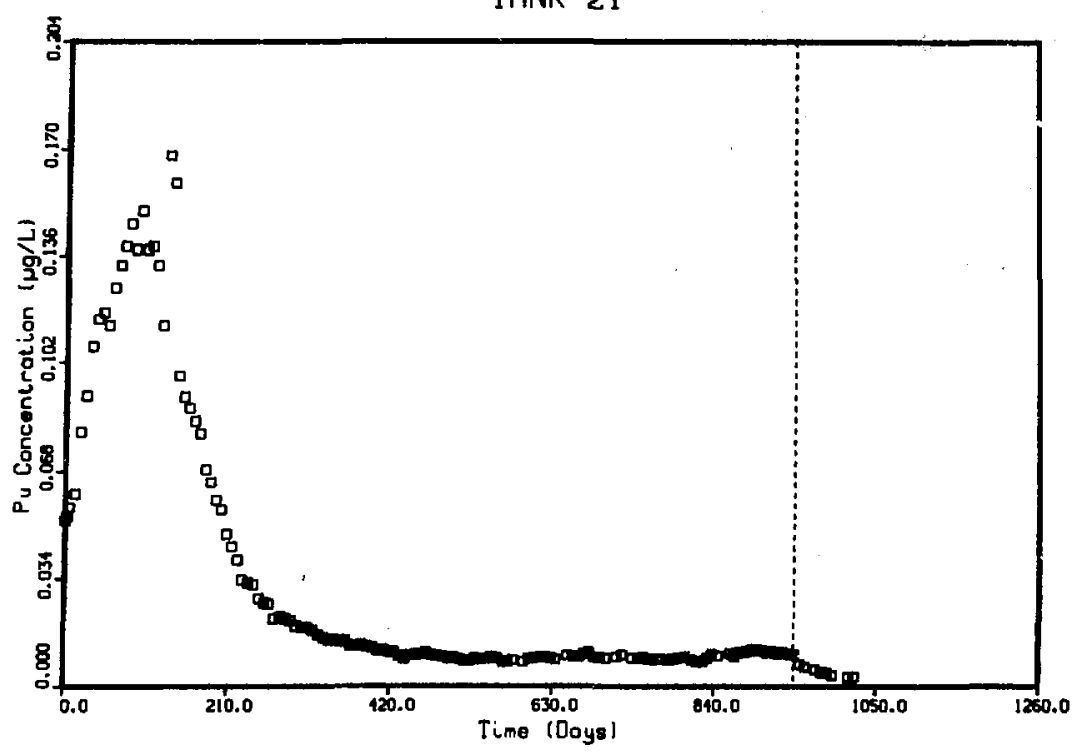

Fig. 9. Plutonium concentration versus time for aquarium number 21 (warm sea water with a 33.6-g source). The vertical dashed line indicates removal of the source from the aquarium.

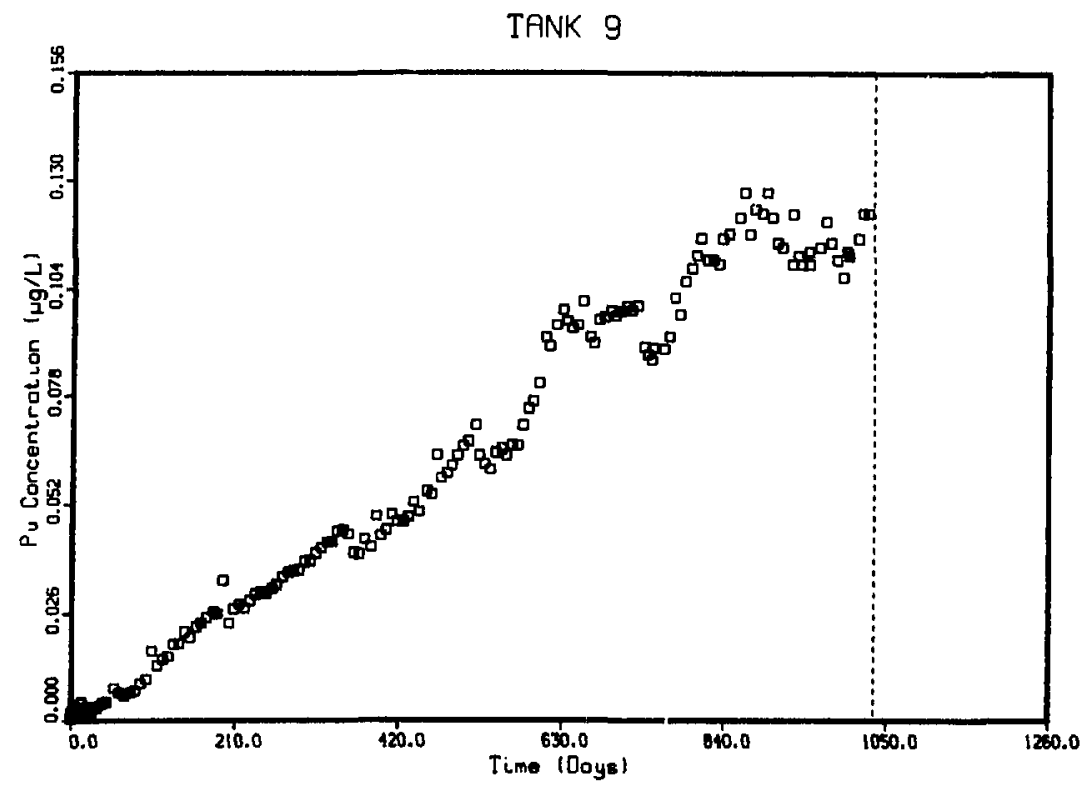

Fig. 10. Plutonium concentration versus time for aquarium number 9 (warm sea water with a 6.2-g source). The vertical dashed line indicates removal of the source from the aquarium. 
containing warm sea water showed less scatter but similar patterns. The noteworthy exception is the warm sea water with the 64-g PPO source (Fig. 8): a large, nearly symmetrical peak occurred late in the experiment. Although this behavior is difficult to explain, we think it is caused by a change in the surface area or surface condition of the source. The times required to reach the peaks of the concentration curves were highly variable and do not seem to fit any pattern.

In most cases, the apparent plutonium release rates from the fuel pellets are not constant. Consequently, calculating average release rates from the plutonium concentration in the water at any given time can give misleading results. The fact that the plutonium concentr ation in the water decreases at various times during the experiment indicates that plutonium removal processes must be at work, so the transfer of plutonium trom the water to the walls of the aquarium, the sediment, or elsewhere occurs at a significant rate. The erratic data observed in several aquaria indicate that at least one important rate-determining factor is not being controlled in these experiments. These observations imply that plutonium release into the water is not a simple, homogeneous process. For these reasons and others discussed later, we hypothesize that the release is partially a physical process that depends on the surface conditions at the fuel pellet-water interface.

Within the uncertainty of the data, the power level (size) of the source does not seem to be an important factor in determining the release rate per unit area. This tentative conclusion is in contrast to results from terrestrial experiments, in which large fuel pellets can exhibit high release rates during rainfall. These high release rates probably are caused by the action of boiling water on the pellet surface, which results in physical ejection of particles. However, in the present experiment the water has a sufficient heat capacity to cool the surface of the source below the boiling point. Although significant thermal gradients are present, the violent surface conditions that can exist during a terrestrial rainfall do not occur.

Curve slopes were determined for various portions of the curves by manual curve-fitting techniques (see Table I). The slopes are presented in terms of plutonium concentration per time normalized to the geometric surface area of the sources. Because each aquarium contained $75 \mathrm{~L}$ of water, the concentration values can be converted directly to the total plutonium contents of the waters. Two slopes are listed: the slope of the curve early in the experiment (before the

\begin{tabular}{|c|c|c|c|c|c|c|}
\hline \multirow[b]{2}{*}{$\begin{array}{l}\text { Aquarium } \\
\text { Number }\end{array}$} & \multirow[b]{2}{*}{$\begin{array}{l}\text { Source } \\
\text { Mass } \\
\text { (g) }\end{array}$} & \multirow[b]{2}{*}{ Water" } & \multicolumn{2}{|c|}{ Rates $1^{b}$} & \multicolumn{2}{|c|}{ Rates $2^{\mathrm{d}}$} \\
\hline & & & $\left(\begin{array}{l}(p g / L) \\
m^{2} / s\end{array}\right)$ & $\left(\begin{array}{c}n g \\
m^{2} / s\end{array}\right) c$ & $\left(\begin{array}{l}\mathrm{pg} / \mathrm{L} \\
\mathrm{m}^{2} / \mathrm{s}\end{array}\right)$ & $\left(\begin{array}{c}n g \\
m^{2} / s\end{array}\right) c$ \\
\hline $\begin{array}{r}5 \\
24 \\
11\end{array}$ & $\begin{array}{r}63.2 \\
33.6 \\
6.3\end{array}$ & $\begin{array}{l}\text { cold fresh } \\
\text { cold fresh } \\
\text { cold fresh }\end{array}$ & $\begin{array}{l}527 \\
230 \\
201\end{array}$ & $\begin{array}{l}39.5 \\
17.2 \\
15.1\end{array}$ & $\begin{array}{l}399 \\
204 \\
142\end{array}$ & $\begin{array}{l}29.9 \\
15.6 \\
10.7\end{array}$ \\
\hline $\begin{array}{r}13 \\
22 \\
7\end{array}$ & $\begin{array}{r}63.2 \\
33.6 \\
6.1\end{array}$ & $\begin{array}{l}\text { cold sea } \\
\text { cold seos } \\
\text { cold sese }\end{array}$ & $\begin{array}{c}12.9 \\
153 \\
77.4\end{array}$ & $\begin{array}{c}0.970 \\
11.4 \\
5.00\end{array}$ & $\begin{array}{r}6.0 \\
68.1 \\
3.4\end{array}$ & $\begin{array}{l}0.453 \\
5.11 \\
0.256\end{array}$ \\
\hline 23 & 33.5 & warm fresh & 65.7 & 6.43 & 51.4 & 3.86 \\
\hline $\begin{array}{r}12 \\
21 \\
9\end{array}$ & $\begin{array}{r}63.2 \\
33.6 \\
6.2 \\
\end{array}$ & $\begin{array}{l}\text { warm sea } \\
\text { warm sea } \\
\text { warm sea }\end{array}$ & $\begin{array}{c}0.816 \\
11.2 \\
3.06\end{array}$ & $\begin{array}{l}0.0613^{\circ} \\
0.838 \\
0.229\end{array}$ & $\begin{array}{l}0.914 \\
0.095 \\
3.06\end{array}$ & $\begin{array}{l}0.069^{\circ} \\
0.007 \\
0.229\end{array}$ \\
\hline \multicolumn{7}{|c|}{ 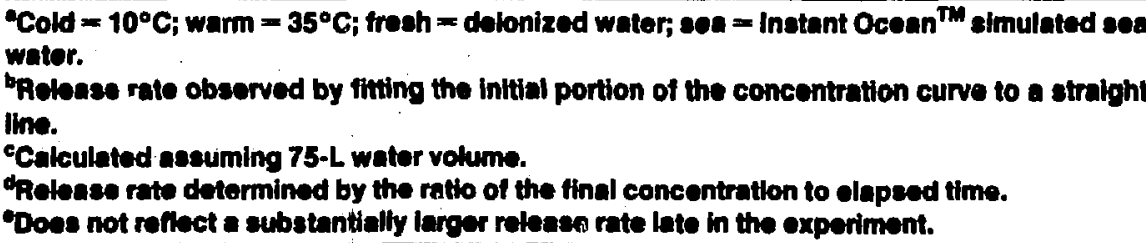 } \\
\hline
\end{tabular}


plutonium concentrations began to decrease) and the slope obtained by dividing the final plutonium concentration by the elapsed time of the experiment. To evaluate the potential environmental impacts of short exposures, the early slopes are more useful, whereas the final slopes probably are more appropriate for long-term effects.

Table I demonstrates that the water composition significantly affects the plutonium release rates. Under comparable conditions, the sea watei aquaria showed significantly lower concentrations of plutonium than did the fresh water aquaria. Water temperature also is important, with colder water having higher plutonium concentrations. These observations agree with those made in earlier experiments. ${ }^{6.7}$ In one case, release rates apparently were higher in fresh water than in normal saline at body temperature. ${ }^{6}$ In that study, which examined the "solubility" of plutonium oxide particulates, the apparent release rates were a little higher than in the present study ( 16.8 to $45.0 \mathrm{ng} / \mathrm{m}^{2} / \mathrm{s}$ in fresh water and 2.3 to $13.1 \mathrm{ng} / \mathrm{m}^{2} / \mathrm{s}$ in normal saline). We attribute the differences between those rates and ours to uncertainties in the surface areas of the sources and to differences in how the rates were calculated. in a separate study, the apparent release rate in $1 \mathrm{M}$ perchloric acid was between 0.73 and $9.5 \mathrm{ng} / \mathrm{m}^{2} / \mathrm{s}^{7}$ In this interesting case the acid, which we might expect to enhance the soiubility of the plutonium, actually gave rise to apparent release rates substantially lower than those in the fresh water case. Although the temperature and compositional dependencies may seem strange, the present experimental results are entirely consistent with those of these past investigations.

If the concentration buildup of plutonium in the aqueous phase were a simple, one-step process, the plutonium concentration should increase with temperature. Because this increase does not occur, the net transfer cannot be a simple process. One possible explanation for this phenome- non is that, once released from the source, the plutonium may be removed from the water by subsequent reactions that have higher temperature coefficients than the release itself. If true, the plutonium would be removed faster in the warm water aquaria, with lower concentrations in the water and a smaller apparent release rate. This also would lead to more plutonium on the walls and in the sediments in the warm water aquaria. In another experiment conducterd in glass chambers, in which the same temperature dopendence of transfer rate was observed, the amounts of plutonium on the walls of the chambers and in the sediments were measured at the conclusion of the experiment. The expected plutonium excesses in the sediments and on the walse were not observed. Thus, it appears that subsequent reactions cannot be invoked to explain the temperature dependencies of the apparent release rate. The plutonium apparently is not escaping from the source as rapidly in the warm water as in the cold water aquaria, or in the salt water as in the fresh water. Thus, the controlling factors must exert their influences at the surface of the source and not in the bulk of the water phase. This may explain the erratic nature of some of the observations, because the condltions at a solid-liquid interface are difficult to control experimentally.

Water from four of the aquaria, those containing the 33.3-g GROG sources, were filtered to determine the particle size distribution of the plutonium (see Table II). Three filters were used, a 1.0- $\mu \mathrm{m}$ pore Nuclepore ${ }^{\mathrm{TH}}$ filter, a $0.1-\mu \mathrm{m}$ pore Nuclepore filter, and a 10000 molecular weight cutoff Amicon filter. The Nuclepore filters were used whenever possible because of their welldefined pore size distribution and because they can be easily dissolved for analysis. For pore sizes smaller than $0.05 \mu \mathrm{m}$, the flow rates are so slow that filtration of samples becomes very time consuming. The Amicon filters, though not having as well-defined pore size distributions as the Nuclepore filters, have much more rapid flow

TABLE II. Filtration Results

\begin{tabular}{|c|c|c|c|c|c|}
\hline $\begin{array}{l}\text { Aquarium } \\
\text { Number }\end{array}$ & Conditions & 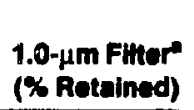 & $\begin{array}{l}\text { 0.1-um Filter } \\
\text { (\% Rotained) }\end{array}$ & $\begin{array}{l}10 \mathrm{~K} \text { imwco Fitter } \\
\text { (\% Retained) }\end{array}$ & $\begin{array}{c}\text { Total } \\
\text { Pu } \\
(\mu \in / 2)\end{array}$ \\
\hline $\begin{array}{l}21 \\
22 \\
23 \\
24\end{array}$ & $\begin{array}{l}35^{\circ} \mathrm{C} \text { sea water } \\
10^{\circ} \mathrm{C} \text { sea water } \\
35^{\circ} \mathrm{C} \text { fresh water } \\
10^{\circ} \mathrm{C} \text { fresh water }\end{array}$ & $\begin{array}{r}25 \\
1 \\
2 \\
6\end{array}$ & $\begin{array}{r}10 \\
1 \\
2 \\
5\end{array}$ & $\begin{array}{r}95 \\
15 \\
3 \\
7\end{array}$ & $\begin{array}{r}0.01 \\
5.5 \\
4.9 \\
19.8\end{array}$ \\
\hline
\end{tabular}

NucleporeTM fiter.

b Amicon PM-10 fiter. 
rates for equivalent pore sizes. The pore sizes of the Amicon filters are described in molecular weight of a chemical standard rather than in terms of a pore diameter. In terms of spherical plutonium oxide particles, the 10000 molecular weight standard would correspond to approximately a 3.3-nm diameter. In performing these filtrations, we experienced some difficulty with sample reproducibility. Excellent recoveries could be obtained for total radioactivity when filters and filtraies were measured and compared with the original aliquot, but considerable variations in the percentage of plutonium retained on the filters were observed with samples from the aquaria. This variability probably was caused by occasional "large" particles of plutonium oxide, containing enough activity to seriously affect the total count but present in fow enough numbers to be sampled nonreproducibly. Consequentiy, although the percentage of plutonium retained on a filter could be determined with confidence for a given sample aliquot, considerable variation was observed among different aliquots from the same tank. In spite of this limitation, some important conclusions can be drawn from Table II.

The values in Table II represent the percentage of the radioactivity in the original sample aliquot retained on the filter. The fact that the 0.1 $\mu \mathrm{m}$ filter sometimes had lower retentions than the 1.0- $\mu \mathrm{m}$ filter attests to the variability among sample aliquots and to the precision of the measurements. Interestingly, Table II shows that most of the plutonium passes through all the filters. The one possible exception is the 10000 molecular woight cutoff filter for tank 21, which shows $95 \%$ retention. In fact, the gross plutonium count for this sample was more than 10 times that for any other aliquot from tank 21. Probably one or more large particies of plutonium oxide in this sample contributed to its high count and were retained on the filter. Thus, the retention for this sample may be anomalously high. One conclusion to be drawn from Table II is that most plutonium particulates in the water are exceedingly fine. A particle that can pass through a 3.3-nm filter is so small that it may possess some characteristics of both particles and solutes. How to model the transport of the released plutonium remains an open question. Further characterization of the plutonium is required, which should be one focus of future experiments.

Metallographic examination of the sources after the conclusion of the experiment reyealed nothing unusual. However, etching the surfaces did show some interesting differences among the sources. This etching procedure, which used a mixture of $\mathrm{HBr}, \mathrm{HCl}$, and $\mathrm{HF}$, normally is done to reveal the grain structure of the source material. In the sea water samples, the etching attacked the surfaces at the ends and circumferences of the pellets to depths of $300 \mu \mathrm{m}$ for the warm water pellet and $\mathbf{5 0} \mu \mathrm{m}$ for the cold water pellet (Figs. 11 and 12). This behavior was not observed for the pellets exposed to fresh water nor for fracture surfaces within the sea water pellets. The significance of these observations is unclear. There are some apparent differences in the surfaces of the pellets, but the amount of plutonium in the affected surface layers is many times that observed in any of the aquaria. One might ask about the nature of the material removed by the etchant. Could the sea water leave deposits in and around the grain boundaries that later would be removed by etching? If this were so, could these deposits trap the released plutonium and prevent its escape from the pellet into the bulk of the solution? Such a hypothesis could explain much of the plutonium release phenomena that we observed during these experiments. However, we require some direct evidence before we can be satisfied with this explanation. The observations are consistent with our contention that the controlling processes are surface phenomena and not solution reactions.

Plutonium can be released from the fuel pellet by chemical or physical processes. If the release occurred primarily by chemical processes, the dependence of the release rate on water composition might be exsily expiained. However, the inverse temperature dependence and the variable plutonium concentration versus time behaviors are incompatible with a strictly chemical mechanism. Chemical dissolution of the plutonium from the surface of the fuel pellet would require a positive temperature coefficient, which was not observed, or a sequence of consecutive reactions to axplain the inverse temperature dependence. This latter situation would lead to larger amounts of plutonium in the sediment or on the walls of the container, because redeposition of all the excess plutonium on the source is unlikely. Since we did not observe such an excess, we conclude that a strictly chemical mechanism does not describe the experimental system.

Physical release mechanisms, all assuming radiation damage as the underlying cause, have been discussed in the literature ${ }^{9-13}$ Clinard and Rohr note that ${ }^{23 \%} \mathrm{PuO}_{2}$ undergoes spontaneous fragimentation with the release of particles ranging from a few millimeters to less than $100 \mathrm{~nm}$.9 


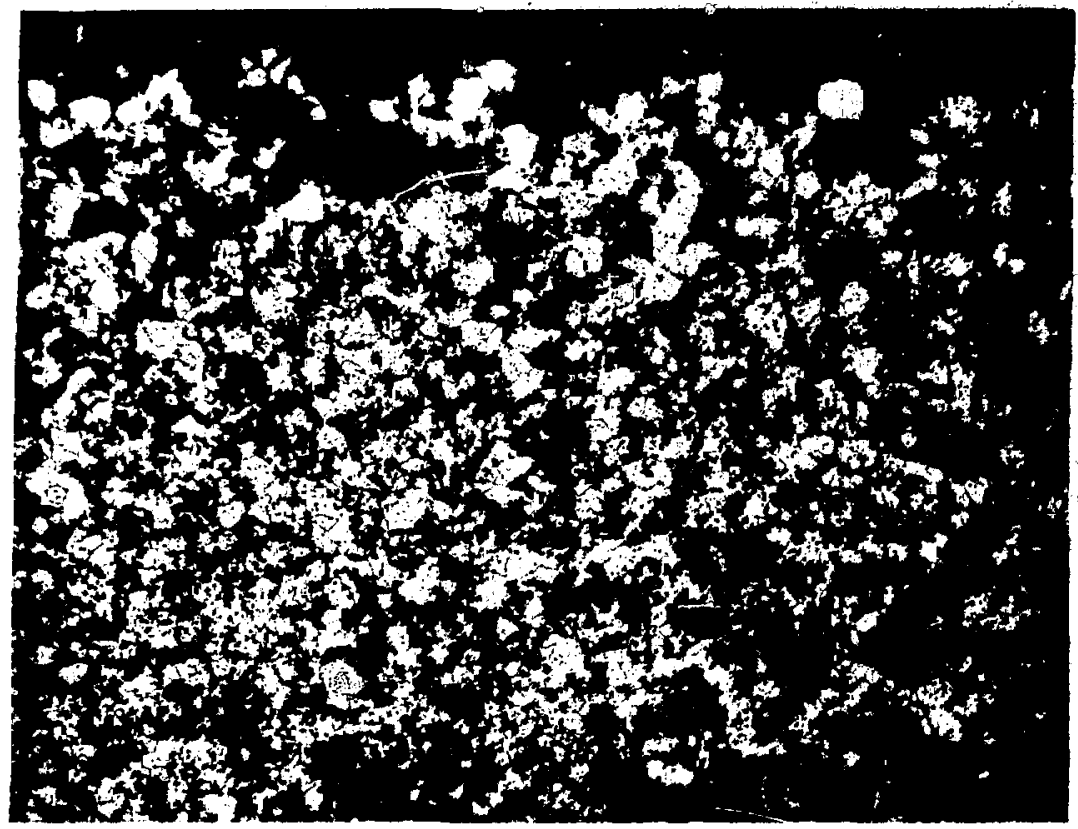

Fig. 11. A section of $\mathrm{PuO}_{2}$ pellet number ET2-6 after etching. This source was exposed to simulated sea water at $35^{\circ} \mathrm{C}$ for 943 days. The effects of the etching treatment are clearly visible at the top edge of the photomicrograph. The magnification is $\mathbf{5 0 X}$.

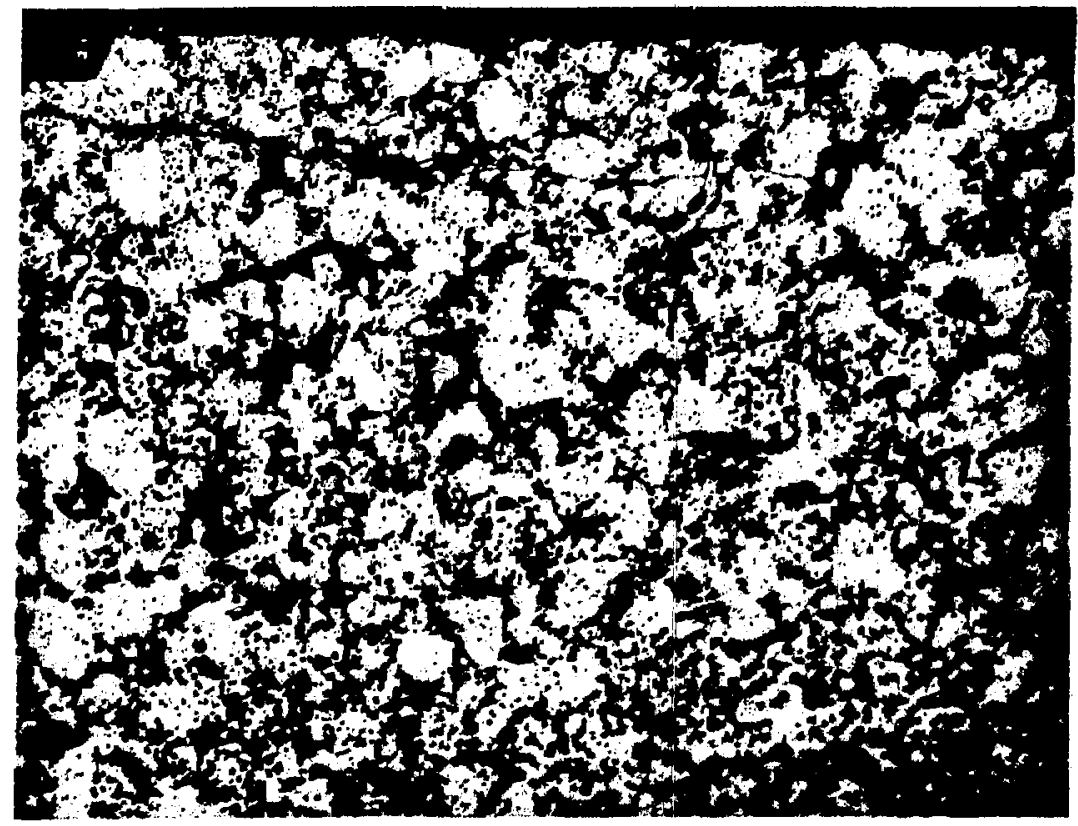

Fig. 12. A section of $\mathrm{PuO}_{2}$ pellet number ET2-4 after etching. This source was exposed to fresh water at $35^{\circ} \mathrm{C}$ for 943 days. Examination of the edge of the source, at the top of the photomicrograph, reveals no evidence vi attack by the etching solution. The magnification is $100 \mathrm{X}$. 
Such behavior was not observed for ${ }^{230} \mathrm{PuO}_{2}$. They considered thermal stresses, lattice damage, and radiotysis of the surrounding medium as possible controlling factors but were unable to pinpoint any of these as solely responsible for the $\mathrm{PuO}_{2}$ fragmentation. Fleischer ${ }^{10}$ and Fleischer and Raabe ${ }^{11-13}$ published four articles in which they discussed the fragmentation and dissolution of $\mathrm{PuO}_{2}$ particles. They noted four possible mechanisms. (1) Recoil nuclei may occur in unusual lattice positions or with unstable valence states that are readily susceptible to leaching by whatever medium the plutonium is in. (2) Water may retard recoil nuclei so that they may come to rest within the pore structure of the solid and thus be available for transport into the surrounding medium. (3) The radioactive decay process may leave recoil damage tracks in the surface of the solid, thus allowing rapid diffusion of soluble species to the surface. (4) The damage created by recoil nuclei may result in fraginented regions on the surface of the solid that later are loosened and mobilized by the liquid. Two of these mechanisms were shown to be operative under various conditions: mechanism 4 under dry conditions and mechanism 2 under wet conditions. ${ }^{13}$ The discussion of experimental results under wet conditions is particularly interesting because the authors observed particles containing from 50 to 10000 plutonium atoms in a power law distribution, with the largest particles being least abundant. ${ }^{11}$ These are extremely small particles that would pass through most mombrane filters. The authors noted that plutonium could be dissolved from the surface of the solid and then undergo coagulation reactions in the liquid phase, but that neither the observed size distribution nor the time behavior was consistent with current coagulation theories.

If the release mechanism is primarily a physical one, the released plutonium should be in the form of Pu(IV), because particles ejected from the source would be $\mathrm{PuO}_{2}$. Adams et al., in a study of the solubility of ${ }^{230} \mathrm{PuO}_{2}$ derived from microspheres, suggested that the plutonium in the water was present as colloidal $\mathrm{Pu}(\mathrm{OH})_{4}$, but that it might also be present, at least partially, in very small fragments of $\mathrm{PuO}_{2}{ }^{14}$ In the same study, the authors attributed erratic results to spallation of small particles of ${ }^{238} \mathrm{PuO}_{2}$ not uniformly distributed in the water. These notions were based on inierences from filtrations and results of plant and animal uptake experiments. A different interpretation was notad by Bondietti and Reynolds, who studied solutions contacted with high-fired $\mathrm{PuO}_{2}$ while also analyzing for piutonium in different oxidation states. ${ }^{15}$ They observed that $95 \%$ of the soluble plutonium in a neutral, dilute carbonate (approximately $10^{-4} \mathrm{M}$ $\mathrm{NH}_{4} \mathrm{HCO}_{3}$ ) solution contacting plutonium dioxide microspheres was $\mathrm{Pu}(\mathrm{V})$ or $\mathrm{Pu}(\mathrm{VI})$ and that only $5 \%$ behaved as Pu(IV). Bondietti and Sweeton elaborated on this work in a later publication. ${ }^{16}$ They noted that during the initial contact the solution phase plutonium was dominated by a "refractory" species displaying the properties of plutonium polymer. The presence of an oxidized plutonium species, whose rate of appearance was nearly constant during the experiment, aiso was obsarved. The overall experiment was described as having an initially high and erratic rate, probably because of the refractory species, and a subsequently slower rate because of the oxidized species. The use of isotopic tracers revealed that oxidation occurs near the oxide surface (probably caused by radiolysis) and not in the bulk of the solution. The authors hypothesized that the actual dissociation of plutonium from the oxide surface was physical and thist oxidation, induced by radiolysis effects, took place during the transfer frnm the solid surface to the bulk solution phase. ${ }^{16}$

These discussions, when considered in the context of our own observations, suggest to us that the controlling mechanism for the release of plutonium from the fuel pellets is a physical one, much like the fourth model suggested by Fleischer and Raabe." Thus, we can envision alpha-decay-induced fragmentation occurring in the surface layers of the solid. Particles then may be loosened or etched by the water, resulting in particulate releases into the liquid phase. This may explain the exceedingly small particle sizes observed and the etching behavior obtained during the post-mortem examination of the source. The time and temperature dependencies require additional controlling factors. We think that reactions may occur at the surface of the solid that tend to stabilize the damaged area against release of particies into the liquid phase. Such reactions would progress faster at higher temperatures and would explain the inverse temperature dependence of the release rate. The composition of the lizuid phase also may have a strong influence on such surface reactions, which would explain the observed dependence of the release rate on the water composition. In sea water, the deposition of compounds from the sea water in the sulface layer might trap plutonium otherwise subject to release and thus give an apparently low release rate. 
The observation by Bondietti and Sweeton of two distinct release rates ${ }^{16}$ is consistent with our experience. Patterson et al. reported that the initial dissolution rate of plutonium oxide is higher and more erratic than the subsequent, longer term rate, which is relatively constant. ${ }^{6}$ The initial, rapid release rate was attributed to reactions of the oxide with the solution. A related mechanism suggested by Bondietti and Sweeton ${ }^{16}$ involving recoil aggregates seems more appropriate. Decay events occurring after calcination of the source would cause a buildup of recoil-derived fragments at the surface. These would be released to the aqueous phase as colloidal material when the source was introduced into water. Such colloidal material would behave, initially at least, as $\mathrm{PuO}_{2}$. Because we have never determined the oxidation states of the released plutonium, nor attempted to determine the colloidal properties of the initially released plutonium, we can only speculate on the validity of these mechanisms. There is an obvious need for fundamental studies of the nature and chemical composition of the surface of the fuel pellet and the solid-liquid interactions taking place there. Also needed are studies to determine the oxidation state and potential colloidal properties of the released plutonium.

\section{CONCLUSIONS}

Experiments were conducted in which ${ }^{238} \mathrm{PuO}_{2}$ pellets of varying sizes were exposed to aqueous environments for extended periods. The results showed that water composition and water temperature are important factors in determining the apparent release rate of plutonium into the water. In cold fresh water experiments, the plutonium levels in the water increased approximately linearly with time, with release rates ranging from 10 to $40 \mathrm{ng} / \mathrm{m}^{2} / \mathrm{s}$. The one warm fresh water system gave similar but more erratic behavior with a release rate between 3.8 and 6.5 $\mathrm{ng} / \mathrm{m}^{2} / \mathrm{s}$. Sea water results were more variable, with typical plutonium concentrations increasing approximately linearly for it time and then decreasing irregularly thereafter. Release rates ranged from 0.3 to $11 \mathrm{ng} / \mathrm{m}^{2} / \mathrm{s}$ for cold sea water and from 7 to $900 \mathrm{pg} / \mathrm{m}^{2} / \mathrm{s}$ for warm sea water. The length or time necessary to achieve the maximum value was variable and did not follow any obvious pattern. The size (power level) of the $\mathrm{PuO}_{2}$ source was not an important factor affecting plutonium release per unit area.
The plutonium released into the water is extremely fine, able to pass through a 10000 molecular weight cutoff Amicon filter (3.3-nm pore size). Such material may exhibit behavior typical oi particles, solutes, or both, depending on its form. An important subject of future research should be better characterization of the released plutonium.

Release rates correlate inversely with the temperature and salinity of the water phase, suggesting that the release mechanism is not a one-step chemical process. Evidence presented contradicts models that assume sequential homogeneous reactions to control mobilization and plutonium removal from the liquid phase. Differences in the surface structures of the fuel pellets observed at the conclusion of the experiments suggest that plutonium release may be controlled by the surface condition of the fuel pellet. The model that seems to best fit the observations is one based on alpha-decay-induced fragmentation of the surface layer of the stilid, followed by loosening and etching of the resulting particles by the liquid medium. The fatter process may depend on water tsmperature and composition. Such a model can explain the small size of the released plutonium particles and the temperature and salinity dependencies observed. However, direct evidence is needed to verify such a mechanism.

\section{ACKNOWLEDGMENTS}

We are most grateful to C. C. Land, D. Pavone, M. A. Casey, and J. M. Herrera, who performed the post-mortem examinations of the plutonium oxide sources and who noticed the important differences among the surfaces of sources exposed to different water types. We also wish to acknowledge E. M. Hodge, J. Bubernak, and $M$. T. Romero, who performed many of the plutonium analyses.

\section{REFERENCES}

1. G. R. Waterbury, "Environmental and Radiological Safety Studies: Interaction of ${ }^{230} \mathrm{PuO}_{2}$ Heat Sources witn Terrestrial and Aquatic Environments, October 1-December 31, 1979," Los Alamos Scientific Laboratory report L_A-8285-PR (March 1980). 
2. G. M. Matlack, J. H. Patterson, and N. D. Stainaker, "Environmental and Radiological Safety Studies: Interaction of ${ }^{230} \mathrm{PuO}_{2}$ Heat Sources with Terrestrial and Aquatic Environments, July 1-September 30, 1982," Los Alamos National Laboratory report LA-9607-PR (December 1982).

3. J. H. Patterson, F. J. Steinkruger, and G. M. Matlack, "Interaction of ${ }^{230} \mathrm{PuO}_{2}$ Heat Sources with Terrestrial and Aquatic Environments: Interim Summary," Los Alamos Scientific Laboratory report LA-8362 (September 1980).

4. J. H. Patterson, G. B. Nelson, G. M. Matlack, and G. R. Waterbury, "Interaction of ${ }^{238} \mathrm{PuO}_{2}$ Heat Sources with Terrestrial and Aquatic Environments," in Transuranium Nuclides in the Environment (International Atomic Energy Agency, Vienna, 1976), pp. 63-78.

5. S. T. Kosiewicz, "Recommendations for Plutonium Colloid Size Determination," Los Alamos National Laboratory report LA-9987 (February 1984).

6. J. H. Patterson, G. B. Nelson, and G. M. Matlack, "The Dissolution of ${ }^{238} \mathrm{Pu}$ in Environmental and Biological Systems," Los Alamos Scientific Laboratory report LA-5624 (July 1974).

7. G. M. Matlack, J. H. Patterson, G. B. Nelson, and G. R. Waterbury, "Dissolution Rates of ${ }^{238} \mathrm{PuO}_{2}$ and ${ }^{239} \mathrm{PuO}_{2}$ in 1 M Perchloric Acid," Los Alamos Scientific Laboratory report LA-6184 (March 1976).

8. J. H. Patterson, F. J. Steinkruger, G. M. Matlack, R. C. Heaton, K. P. Coffelt, and B. Herrera, "Plutonium Release from Pressed Plutonium Oxide Fuel Pellets in Aquatic Environments," Los Alamos National Laboratory report LA-9962-MS (December 1983).

9. F. W. Clinard and D. L. Rohr, "Spontaneous Fragmentation of an Alpha-Active
Ceramic-A Mechanism for Dispersion of Solid Waste?' ' in Scientific Basis for Nuclear Waste Management, J. G. Moore, Ed. (Plenum Publishing Corporation, Now York, 1981), Vol. 3, pp. 405-412.

10. R. L. Fleischer, "On the 'Dissolution' of Respirable $\mathrm{PLO}_{2}$ Particles," Health Physics 29, 69-73 (1975).

11. R. L. Fleischer and O. G. Raabe, "Fragmentation of Respirable $\mathrm{PuO}_{2}$ Particles in Water by Alpha Decay-A Mode of 'Dissolution'," Health Physics 32, 253-257 (1977).

12. R. L. Fleischer and O. G. Raabe, "On the Mechanism of 'Dissolution' in Liquids of $\mathrm{PuO}_{2}$ by Alpha Decay," Health Physics 35, 545-548 (1978).

13. R. L. Fleischer and O. G. Raabe, "Recoiling Alpha-Emitting Nuclei. Mechanisms for Uranium-Series Disequilibrium,' Geochimica et Cosmochimica Acta 42, 973-978 (1978).

14. W. H. Adams, J. R. Buchholz, C. W. Christenson, G. L. Johnson, and E. B. Fowler, "Studies of Plutonium, Americium, and Uranium in Environmental Matrices," Los Alamos Scientific Laboratory report LA-5661 (January 1975).

15. E. A. Bondietti and S. A. Reynolds, "Field and Laboratory Observations on Plutonium Oxidation States," in Proceedings of an Actinide-Sediment Reactions Working Meeting at Seattle, Washington on February 10-11, 1976, L. L. Ames, Ed., Battelle Pacific Northwest Laboratories report BNWL-2117 (1976), pp. 505-537.

16. E. A. Bondietti and F. H. Sweeton, "Transuranic Speciation in the Environment," in Transuranics in Natural Environments, M. G. White and P. B. Dunaway, Eds. (Energy Research \& Development Administration, Las Vegas, June 1977), NVO-178, pp. 449-476. 


\section{APPENDIX: SUMMARY OF EXPERIMENTAL DATA}

\begin{tabular}{|c|c|c|c|}
\hline Ion & $\begin{array}{c}\text { Concertuntion } \\
\text { (pom) }\end{array}$ & Ion & $\begin{array}{c}\text { Concenirion } \\
\text { (opm) }\end{array}$ \\
\hline 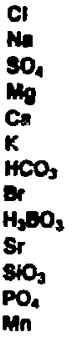 & $\begin{array}{r}13400 \\
10220 \\
2518 \\
1238 \\
340 \\
370 \\
142 \\
60 \\
25 \\
6 \\
3 \\
1.3 \\
1.2\end{array}$ & 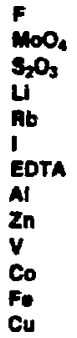 & $\begin{array}{l}1.0 \\
0.8 \\
0.3 \\
0.2 \\
0.10 \\
0.07 \\
0.05 \\
0.04 \\
0.02 \\
0.02 \\
0.61 \\
0.01 \\
0.003\end{array}$ \\
\hline
\end{tabular}

Spoctic onvity 1.025 at $15^{\circ} \mathrm{C}$.

Dote Irom Aquarium Syatems, inc., a141 Tylur thd., Memior, OH 44080.

\begin{tabular}{|c|c|c|c|c|c|c|c|c|c|c|c|c|}
\hline \multirow{2}{*}{\multicolumn{2}{|c|}{ Aquerium Source }} & \multirow{2}{*}{$\begin{array}{l}\text { Lengthe } \\
\text { (min) }\end{array}$} & \multirow{2}{*}{$\begin{array}{l}\text { Diamotor } \\
\text { (mm) }\end{array}$} & \multirow{2}{*}{ (g) } & \multicolumn{3}{|c|}{ Fobrication } & \multicolumn{5}{|c|}{ 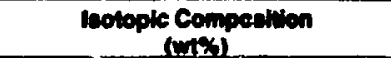 } \\
\hline & & & & & $(\mathrm{mm})$ & $(\mathrm{mo} / \mathrm{yt})$ & Type & & 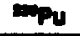 & & & \\
\hline $\begin{array}{r}5 \\
7 \\
0 \\
11 \\
12\end{array}$ & $\begin{array}{l}\text { HPZ-111-1 } \\
\text { HPZ-3-3 } \\
\text { HPZ-60-3 } \\
\text { MPZ-60-2 } \\
\text { HPZ-50-2 }\end{array}$ & $\begin{array}{c}19.77 \\
4.27 \\
4.231 \\
4.246 \\
18.47\end{array}$ & $\begin{array}{l}20.29 \\
13.65 \\
13.705 \\
13.703 \\
20.97\end{array}$ & $\begin{array}{r}63.216 \\
6.155 \\
6.210 \\
6.207 \\
83.247\end{array}$ & $\begin{array}{r}1910 \\
477 \\
477 \\
477 \\
1900\end{array}$ & $\begin{array}{l}1 / 75 \\
0 / 72 \\
3 / 74 \\
3 / 74 \\
3 / 74\end{array}$ & PPo & 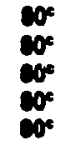 & $\operatorname{man}_{n}^{n}$ & $\begin{array}{l}\mathbf{m} \\
\mathbf{n} \\
\mathbf{n} \\
\mathbf{n n}\end{array}$ & na & $\begin{array}{l}\text { no } \\
\text { ne } \\
\text { ne }\end{array}$ \\
\hline $\begin{array}{l}13 \\
21 \\
22 \\
23 \\
24\end{array}$ & $\begin{array}{l}\text { HPZ-59-4 } \\
\text { ET-2-6 } \\
\text { ET-1-5 } \\
\text { ET-2-4 } \\
\text { ET-2-2 }\end{array}$ & $\begin{array}{l}19.49 \\
12.82^{c} \\
12.82^{c} \\
12.82^{c} \\
12.82^{c}\end{array}$ & $\begin{array}{l}20.34 \\
17.0 \% \\
17.006 \\
17.0 \% \\
17.0 \%\end{array}$ & $\begin{array}{l}63.229 \\
33.6 \\
33.6 \\
33.5 \\
33.6\end{array}$ & $\begin{array}{l}1800 \\
1350 \\
1340 \\
1350 \\
1350\end{array}$ & $\begin{array}{l}3 / 74 \\
3 / 81 \\
3 / 81 \\
3 / 41 \\
3 / 81\end{array}$ & 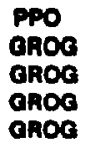 & 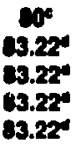 & $\begin{array}{c}14.14^{\circ} \\
14.14^{\circ} \\
14.14^{4} \\
14.14^{4}\end{array}$ & $\begin{array}{l}2.04 \\
2.04 \\
2.04 \\
2.04\end{array}$ & $\begin{array}{l}0.49 \\
0.49 \\
0.44 \\
0.44\end{array}$ & $\begin{array}{l}0.15 \\
0.15 \\
0.15^{4} \\
0.15^{4} \\
0.15^{\circ}\end{array}$ \\
\hline
\end{tabular}

-All sourees were right, cireular eylindtern.

-PPO = pressed plutonium oxide; ORCO - PPO using mixed partichs elzes.

ENominal values.

On 6/18/80.

\begin{tabular}{|c|c|c|c|c|c|c|c|c|}
\hline \multirow[b]{2}{*}{$\begin{array}{l}\text { Aquarium } \\
\text { Number }\end{array}$} & \multirow[b]{2}{*}{ Water } & \multirow[b]{2}{*}{$\begin{array}{c}\text { Tempereture } \\
\left.{ }^{\circ} \mathrm{C}\right)\end{array}$} & \multicolumn{3}{|c|}{ Sounce } & \multirow[b]{2}{*}{$\begin{array}{l}\text { Soures in } \\
\text { (mo/dey/or) }\end{array}$} & \multirow[b]{2}{*}{$\begin{array}{l}\text { soures out } \\
\text { (mo/gen/or) }\end{array}$} & \multirow{2}{*}{ Timind } \\
\hline & & & Nunneer & $\begin{array}{c}\text { Mens } \\
\text { (o) }\end{array}$ & $\begin{array}{l}\text { Area } \\
\left(\operatorname{mom}^{2}\right)\end{array}$ & & & \\
\hline $\begin{array}{r}5 \\
7 \\
9 \\
11 \\
12 \\
13 \\
21 \\
22 \\
23 \\
24\end{array}$ & 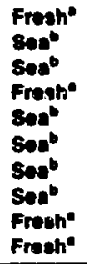 & $\begin{array}{c}12 \\
10 \\
37 \\
10 \\
37 c \\
10 \\
35 \\
10 \\
35 \\
10\end{array}$ & $\begin{array}{l}\text { HPZ- } 111-1 \\
\text { HPZ-3-3 } \\
\text { HPZ-60-3 } \\
\text { HPZ-60-2 } \\
\text { HPZ-59-2 } \\
\text { HPZ-59-4 } \\
\text { ET-2-6 } \\
\text { ET-1-5 } \\
\text { ET-2-4 } \\
\text { ET-2-2 }\end{array}$ & $\begin{array}{l}3.22 \\
6.2 \\
6.29 \\
6.29 \\
63.25 \\
63.23 \\
33.6 \\
33.6 \\
33.5 \\
33.6\end{array}$ & $\begin{array}{r}1910 \\
477 \\
477 \\
477 \\
1900 \\
1930 \\
4350 \\
1340 \\
1350 \\
1350\end{array}$ & $\begin{array}{l}01 / 20 / 75 \\
03 / 31 / 72 \\
03 / 20 / 74 \\
03 / 20 / 74 \\
10 / 25 / 74 \\
10 / 25 / 74 \\
03 / 27 / 21 \\
03 / 27 / 21 \\
03 / 27 / 21 \\
03 / 27 / 21\end{array}$ & 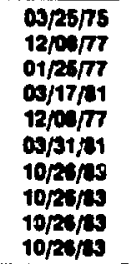 & 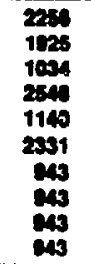 \\
\hline
\end{tabular}

